\title{
The Children's Rights, Multiculturalism and Their Implementation for the Education of Roma Children
}

\author{
Ndricim Mehmeti (PhD)* \\ Bedri Kola (PhD) (Prof. As.)* \\ *Department of Science Education at "Albanian University", Tiranë \\ Email: cimmehmeti@yahoo.com
}

Doi:10.5901/ajis.2015.v4n2s2p182

\begin{abstract}
One of the most significant concerns not only for Albania but even beyond, is the consideration of educational, social, political and economic rights of the Roma community in the locations where they live. Albania has a presence a Roma community in some of its regions, especially in the capital and in its major cities. The principles of multiculturalism, education and the rights of Roma children, naturally, have undergone significant changes in the period after 1990, in Albania. Ministry of Education in cooperation with national and international organizations in compliance with the most essential documents of the Council of Europe, the European Union and others has undertaken a series of initiatives, to facilitate, encourage and promote educational and cultural values of this community. Certainly, there have been problems, delays of some reforms and its measures, but however there has been a good will to move things forward. There are, still, representation problems by the Roma Community associations, and related issues regarding ways of handling educational rights by the local government units and other related bodies. This article provides an overview of the main educational issues of the Roma Community including the role of institutions, teachers and pupils.
\end{abstract}

Keywords : Multiculturalism, Roma Community, Council Of Europe, European Union.

\section{Introduction}

While missing the source of reliable data providing the exact time when the Roma people have come to Albanian, assumptions of the historians place their establishment in this country between the XIII and XV Century. Similar to other Balkan countries, although Roma have usually lived on the peripheries of these societies, as a general rule they have not been the object of policies aiming at their elimination. While there is just a few documented information and data on the way Roma people have been treated in Albanian during the World War II, it seems that the Roma population was saved from mass destruction as a result of delays conducted by the local fascist authorities (Kolsti 1991). Roma did not have an official status as a separate group in the People's Socialist Republic of Albania. However, Roma community nowadays in Albania is officially known as an ethno-linguistic minority, while the 2001 Census did not include any questions on ethnicity and linguistic identity in its content. According to unofficial estimated data, the number of Roma in Albania varies from 80,000 to 150,000 , which consists between $2.5 \%$ and $4.7 \%$ of the total population of 3.8 million. The assumed increase of Roma population is $3 \%$ higher than that of the Albanian population which is about 1.9\%. (UNDP Albania, 2006). Roma population are spread almost all over the country (mainly in segregated neighborhoods) or in villages near major cities. The largest number of Roma is concentrated in the central and southeastern areas of Tirana, Durres, Elbasan, Fier, Berat, Korca, Pogradec, Bilisht, Gjirokastra, Delvinës, Kruja and Shkodra (Albania UNDP, 2006).

\section{Research Methodology}

The article is a theoretical study, based on work experiences as officials at the Ministry of Education and Science (now the Ministry of Education and Sports) and it focuses on offering information by making a comparison between the requirements set by the international institutions on education for Roma and their implementation in the Albanian context.

\section{The European Convention for the education of Roma}

The European Cultural Convention was ratified in 1954. This international treaty is open to European countries that are 
not members of the Council of Europe, and enables them to participate in the Council's programs on education, culture, sport and youth.

The four specialized committees - the Steering Committee for Education, the Committee on Higher Education and Research, the Committee on Culture and the Committee on Cultural Heritage carry out tasks pertaining to education and culture in compliance with the European Cultural Convention. It also maintains a close working relationship with the conferences of European Ministers for education, culture and cultural heritage. The programs of these four committees comprises an integral part of the work of the Council of Europe and, like the programs in other sectors, they all contribute to the accomplishment of the three main policy objectives of this organization:

- Protection, reinforcement and promotion of human rights and fundamental freedoms of a pluralist democracy;

- Awareness promotion of the European identity;

- Striving for a common response to the great challenges faced now by the European society.

"The education programme of the Steering Committee for Education and the Steering Committee for Higher Education and Research currently covers school, out-of-school and higher education. At present, there are projects on education for democratic citizenship, history, modern languages, school links and exchanges, educational reform strategies, inter-religious and intercultural dialogue, training for educational staff, the recognition of qualifications, lifelong learning for equity and social cohesion, universities as sites of citizenship, learning and teaching in the communication society, education for Roma/Gypsy children in Europe, the teaching of the Holocaust and the heritage of European universities."

But what could be the practical measures to implement these objectives set by this Convention as well the other relevant ones in Albanian reality?

\section{Education Funding}

The Government's spending on education accounted for about 3.5\% of GDP (Gross Domestic Product) in 2008 (Turin: European Training Foundation, 2010). This positions Albania below the average level of OECD (Organization for Economic Cooperation and Development) which estimates about 5.7\%. (Paris: Organization for Economic Co-operation and Development, 2010).

Operating costs for schools, including maintenance of school buildings, water, electricity and telephones, are covered by funds transferred by the Ministry of Finance to the Local Government Units in the form of a grant. This grant, whose amount depends on the population, the specific area and the level of urbanization, it is not spent particularly for education sector, as it also assumed that the Local Government Units should also cover some other public services within their ares. (Washington, DC: World Bank, 2005).

\section{Education through the principles of cooperation and tolerance.}

- it should be included into the educational policies which are closely connected with the development and progress of the young people, in the perspective of building together with them, a Europe of tomorrow, as well as with the peaceful development of human societies into the global perspective, in the spirit of creating a mutual understanding and trust;

- it should allow young people to develop intellectual ability to analyze and interpret critically and responsibly the given information, through dialogue, researching historical facts and through establishment of an open debate based on multiperspectivity, especially on controversial and sensitive issues;

- it should enable European citizens to emphasize their individual and collective identity through the recognition of the historical and cultural heritage which is common to the size of the local, regional, national, European and world.

- it should include the elimination of prejudices and stereotypes, emphasizing into the programs a positive and mutual influences between different countries, religions and school of thoughts which help the historical development of a particular country into the wider European context;

\section{Learning about the human rights at an early age}

Learning on concepts related to human rights issues it can and should be acquired at an early age. For example, introduction on the non-violent resolution of a conflict and the need to respect other people, it can be an experience that 
can happen during preschool years or during first grade (Rec. The EC, 1985). Based on this recommendation and aiming at focusing mostly on the protection of children who come from marginalized groups, it would be appropriate that teaching process should be focused on the prevention of the following phenomena:

- Calling to one another - people/pupils by name using gender, race, skin color, which is mostly know as prejudices;

- The exclusion of others from the class / game / activity because of discrimination reasons;

- The rejection of the presence of a companion / friend in the same school desk/ eating table/ because of their color, race and ethnicity;

- Conflicts which might rise because of race, color, ethnicity or social status.

\section{What should we educate children at a younger age?}

- Helping them to start to understand those kinds of rights which they enjoy regardless of what kind of race, ethnicity, color they belong to;

- Trying to teach them understand that people are not judged by the way they are dressed, their color and race but they are judged by values which they choose to follow in the society where they are living;

- The educators and teachers should organize inclusive activities such as: using traditional clothes (which are prepared by the help of the parents' children), art, music etc.;

- Help children to be able to discover what are the similarities among various issues and learn how to respect their differences;

- Help children to be open in the society they belong by using no prejudice to anyone.

\section{Organization of teaching based the values of intercultural education}

The teaching process using the intercultural values should include evidence of a set of values accepted universally, across groups such as:

Human Dignity: Students should understand and learn the role of values of other people and the role of personal value in the social, cultural, linguistic field as well in that of the family tradition. Simply stated, it should reflect the fact that as everyone has respect for his own dignity; to the same extent he/she should respect the dignity of others in the aforementioned areas;

Curiosity: students should an interest in issues related to how better live in a multicultural society.

Evaluation of different cultures: Students/pupils should support the positive aspects of national traditions and at the same time, they should examine them critically and constructively whenever appropriate. Further, they should also learn about the traditions, different cultures and identities. In this case, a group of teachers of subjects such as History, Civic Education / Citizenship, Geography, Sociology, etc., can very well combine open classes to teach their students on values of coexistence of Albanians and Roma people, stating the contribution of Roma to the fields such as: handicrafts, music, art etc. This will further increase the interest of children and students to respect and recognize the values that Roma community present in their society;

Justice and truth: Students should evaluate the principles and the role of democratic processes. The process of teaching should be focused on encouraging them to be willing to work for a better world and to challenge prejudices, intolerance, discrimination and conflict's mentalities;

Understanding: Students should try to consider and value the feelings and views of others, especially those from people who might be in situations and cultures which are different from their own;

Solidarity: students should be willing to help others, especially people who have problems and difficulties, or come from cultures different from their own. It is accepted that we all need solidarity, especially in various circumstances and stages of our lives. But the need to provide solidarity to the specific population and non-native groups or people who are far from the economic, social and educational level of/from the rest of society, it always remains sensitive. Formation of such concepts makes a considerate effect on the progress of the society itself, it also facilitates the school to become a more open institution and finally it helps students/pupils to establish close and constructive relationships among each other. 


\section{The obligations of a school director and teacher to assess cultures, races and the affiliation of a certain ethnic group or cultural community.}

The following rights and obligations, in their principal usage, for the education of children without exception are all recognized and applicable in our schools. However in many cases it has been presented a kind of reluctance to accept the Roma children into the schools or kindergartens. This comes as a result of the mentality of some school directors and teachers to avoid the work/education with "difficult students". On the other hand, a considerate part of teachers and school leaders justify this conduct with the pressure that is made by the community of other parents. The more elusive it becomes the case when there is no cooperation between schools, Roma associations and organizations operating in the field in education and care for Roma children. This practice can and it should be avoided. Instructions and orders from the Ministry of Education as well as the provision of cooperation of associations should be seen as a reliable basis upon which it should be established a long-term, stable and clear goal cooperation which should be attainable for everyone. Above all, teachers themselves should include as part of their work, activities which promote productive actions which should facilitate the education for Roma children. Such activities may include:

\subsection{Promotion of Interculturalism values includes a number of aspects such as:}

- To work actively to develop these values means helping to create an open, supportive and equal atmosphere at schools;

- The coordination and working links between school and community should be improved in order to prevent insult, vandalism, racial or sexual exploitation, the antisocial behavior of individuals or groups and they should not be tolerated under no circumstances;

- Avoiding the verbal and psychological pressures in school, striving to increase the spirit of an integrated school for all, promote the mutual respect, all of these should part of the school's mission and objectives and in accordance with the values that Interculturalism education and acceptance of human diversity conveys to all.

- A school which addresses the respect of the rights, it should first respect the rights of students/pupils. The schools cannot achieve its mission to educate the best values that a democratic society represents without having the respect for the rights of students, without fully accepting their cultural diversity, without the support of vulnerable communities, where the Roma students is more evident than others.

\subsection{Some activities to help promote the values of the Roma Community.}

Some activities that can be developed in this direction are possibly multifaceted and available to be developed. Some of the main ones are listed as below:

- Providing opinions, organizing debates on topics such as: "The historical period in which Roma population has been settled in Albania"; or "The traditional clothes of Roma Community "; "Rites of marriage in Roma families"; "Preservation of cultural and linguistic heritage to the Roma". These types of topics will enable the exchange the ideas and opinions on various uncovered aspects and it may bring new information from their world and passions of their lives.

- Teachers should encourage curricular projects that address exactly issues of the Roma community in the region where the school is located, or in the neighborhood and even in the class where the students are. Issues such as "Are there any Roma student/pupils in the classroom? Why they are not here? Are we the ones who should have not make the efforts to bring them here, or let them know us better?

- Promoting solidarity: Can we create a social club at school so that they can collect a modest allowance and urge local business employees to support for the professional training of the Roma peers;

- Organize visit to Roma families of our peers/friends. An afternoon between the communities;

- Perform community service modules for high school students, near Roma communities;

- Offer volunteering assistance to organizations which should operate in support of Roma children etc.

\section{Problems arising from the failure of intercultural education in marginalized groups}

The consequences arising from indifference, insufficient, leaving behind from the daily work of the education of the Roma 
community (as well as all education other students), it can be various. Some of those can be listed as below:

- Risking the increase probabilities for dropping out of school;

- The possibility of increasing xenophobic behavior;

- Violation of the rights of students;

- Inequality in educational opportunities which favorites one group towards the other;

- The inability to reach a adequate level of education;

- Increase opportunities to become contingent of trafficking crime groups, or use of child labor and/or sexual exploitation;

- Inability to integrate into the society and social life;

- Self-isolation of the individual / specific groups in society etc.

\subsection{How can we prevent these phenomena?}

In order to prevent these types of phenomena it is impossible that only education units, schools or teachers on their own can come out with positive results. In this context it is important to be open and willing to cooperate with all the relevant groups and institutions: Local government units, Roma associations, associations operating in the field of Roma children rights and their integration into the society, parent's community, business community, central and local educational institutions etc. This work will consist in the following areas:

- Create of an advisory group with parents, teachers, students and representatives of the Regional Education Departments / Offices of Education, to help the integration and education of Roma children;

- Collaborate with local authorities and associations to help Roma children to identify educational age group and create all the opportunities to enroll to classes;

- Use more effectively the second chance programs/projects and provide optimal conditions for their school attendance;

- Organize training sessions and active participation of the Education Departments / Offices of Education personnel in seminars and workshops supported by professional non-governmental associations operating in this sector;

- Facilitate an active participation and open the doors of the schools for activities organized by the organizations which are in support of Roma community;

- Increase the awareness of all teaching staff, psychologists and sociologists who operate in schools, on the necessity of supporting the community of Roma children;

- Support the active participation of parents of Roma children in the School Board;

- Create an annual calendar of activities open to Roma children with the participation of all the above mentioned actors.

\section{Conclusions}

As stated above, it is natural that not everyone can have the opportunity to achieve immediate results. It is important to change the mentality and then allow that by providing all our contribution we would be able to see some good results. We must establish in our school the principle that "We have to fight not only for ourselves but also for those who have no power and who are unable to fight for their rights". In other words, the violation of the rights of others is also a violation of our rights. Inability and denial of opportunity of each individual to be educated and to be equal to others, it is the greatest offense that may be made to the rights of the individual or to a specific group. We are convinced that the figure of a teacher as being the one more caring and noble of every society will know how to give the best model in this regard. On the other side, the civil itself, politics, media, should support a long-term plan of actions, on how to go in bridging the gap that separates the Roma children from the other children in terms of education.

\section{References}

The Council of Ministers, the National Strategy for Improving the Living Conditions of the Roma Community (Tirana, Official Gazette, 2003). United Nations Development Programme in Albania, At Risk: The Social Vulnerability of Roma in Albania [At Risk: Social Vulnerability of Roma in Albania]. (Tirana, Albania UNDP, 2006).

Halil Dundar et al., Poverty and Education in Albania: Who Benefits from Public Spending [poverty and education in Albania: Who 
benefits from public funds] (Washington, DC: World Bank, 2005).

Donald Kenrick, Gypsies: From India to the Mediterranean [Roma: from India to the Mediterranean] (Toulouse: Gypsy Research Center I CRDP Midi Pyrenees, 1993); John Kolsti, "Albanian Gypsies: The Silent Survivors [Albanian Roma: Silent Survivors]" in David Crowe and John Kolsti (ed.), The Gypsies of Eastern Europe [Roma of Eastern Europe] (ARMONK: ME Sharpe, 1991 ); George C. SOULIS, The Gypsies in the Byzantine Empire and the Balkans in the Late Middle Ages [Roma in the Byzantine Empire and the Balkans at the End of the Middle Ages], Dumbarton Oaks Papers, no. 15 (1961): 142-65.

Estevan Peas, Bardulj Moses, and Kseanela Sotirofski, Mapping Policies and Practices for the Preparation of Teachers for Inclusive Education in Contexts of Social and Cultural Diversity: Albania Country Report [planning policies and practices for the preparation of teachers for inclusive education in the context of social and cultural diversity: Country Report for Albania] (Turin: European Training Foundation, 2010).

John Kolsti, "Albanian Gypsies: The Silent Survivors [Albanian Roma: Silent Survivors]" in David Crowe and John Kolsti (ed.), The Gypsies of Eastern Europe [Roma of Eastern Europe] (ARMONK: ME Sharpe, 1991).

Organisation for Economic Co-operation and Development, Education at a Glance 2010: OECD Indicators [Education at a Glance 2010: OECD Indicators] (Paris: Organisation for Economic Co-operation and Development, 2010).

Recommendation of the Committee of Ministers of Education of the Council of Europe, in December 1985.

United Nations Development Programme in Albania, At Risk: The Social Vulnerability of Roma in Albania [At Risk: Social Vulnerability of Roma in Albania]. (Tirana, Albania UNDP, 2006).

Anex:

Legal and normative acts from the Ministry of Education and Sport which are mandatory to be implemented by the Regional Educational Directorates and Education Offices in the country:

Constitution of the Republic of Albania, Article 57, Article 59.

Universal Declaration of Human Rights.

Law No. 69/2012 dated 21.06.1995, "On the Pre-University Education System in the Republic of Albania".

Law on Higher Education in the Republic of Albania;

Law on Vocational Education and Training;

Decree of Council of Minister Nr.1087 dated 28.10.2009 "The adoption of a national plan of action "Decade of Roma Inclusion 2010$2015^{\prime \prime}$

Decree of the Council of Minister Nr.586, dated 07.07.2010, "Defining the university quotes and tuition fees in public higher education institutions, for the first cycle of full-time study as well as tuition fees for the 2010-2011 academic year."

Order no. 170 dated 21.04.2008. "On the functioning of psychological services in Secondary Education/pre-university education ". Instruction no. 34, dated 08.12.2004 "On the implementation of the project" Second Chance ".

Instruction no. 06, dated 29.03.2006 "On registration of Roma pupils in schools that are not equipped with a birth certificate."

Instruction no. 22, dated 01.09.2006, the Minister of Education and Science, "For the implementation of plans, programs and textbooks of secondary education in the 2006-2007 school year", which required all RED / EO, to report (written format) twice per year, aiming at improving the living conditions of the Roma community.

Order of the Minister of Education no. 410, dated 08.11.2006, "On the identification of the situation and measures to be taken in the fight against illiteracy". 